\title{
Mancha de Pestalotiopsis em Helicônia: Caracterização da Doença e Potenciais Fontes de Resistência
}

\author{
Ilka Márcia R.S. Serra \& Rildo S.B. Coelho \\ ${ }^{1}$ Departamento de Agronomia/Fitossanidade, Universidade Federal Rural de Pernambuco, Dois Irmãos, CEP 52171-900, \\ Recife, PE, e-mail: ilka.tt@gmail.com
}

Autor para correspondência: Ilka Márcia R.S. Serra

SERRA, I.M.R.S. \& COELHO, R.S.B. Mancha de Pestalotiopsis em helicônia: caracterização da doença e potenciais fontes de resistência. Fitopatologia Brasileira 32:044-049. 2007.

RESUMO

A "mancha de pestalotiopsis em helicônia" é relatada como uma nova doença para o Brasil e o agente etiológico caracterizado morfologicamente. Avaliou-se a resistência a esta doença em inflorescências de algumas espécies e cultivares ornamentais do gênero Heliconia. O teste de patogenicidade foi feito utilizando-se um isolado oriundo de folhas de $H$. psittacorum x H. spathocircinata cv. Golden Torch, que foi inoculado em folhas e inflorescências destacadas deste mesmo híbrido e cultivar. O comportamento de dez espécies e cultivares de helicônia quanto à susceptibilidade à mancha de pestalotiopsis foi avaliado em inflorescências em pós-colheita e pela inoculação do fungo nas brácteas florais. $\mathrm{O}$ fungo apresentava em meio de cultura acérvulo anfígeno, epidérmico a subepidérmico, conídios fusiformes, medindo 21,0-26,5 x 6,5-8,5 $\mu \mathrm{m}$, com cinco células, sendo as três medianas mais escuras, com três a cinco apêndices filiformes apicais, 8-15 x $1,0 \mu \mathrm{m}$ e pedicelo basal curto, 5,0 x 1,0 $\mu \mathrm{m}$ e foi identificado como Pestalotiopsis pauciseta. Inoculações em folhas e flores destacadas pela deposição de discos de cultura sobre o tecido previamente ferido demonstraram que o fungo em estudo é patogênico e trata-se do agente causal de uma nova doença em helicônia. Quanto à avaliação da resistência à mancha de pestalotiopsis, H. rostrata e H. caribeae x H. bihai cv. Jacquinii foram os materiais mais resistentes dentre os testados, sendo que $H$. rostrata não apresentou nenhuma lesão após a inoculação. A espécie $H$. stricta cv. Las Cruzes foi a mais suscetível, seguida de $H$. wagneriana. Este é o primeiro relato da mancha de pestalotiopsis em helicônia e o primeiro relato da existência de resistência a essa doença em helicônia.

Palavras-chave adicionais: plantas ornamentais, patogenicidade.

\begin{abstract}
Pestalotiopsis spot in heliconia: disease characterization and potential sources of resistance

This study describes a new disease of heliconia, "Pestalotiopsis spot", outlines the morphology of the fungus and presents results from the evaluation of resistance of some heliconias to the pathogen. Pathogenicity of an isolate obtained from diseased foliage of $H$. psittacorum $\mathrm{x} H$. spathocircinata $\mathrm{cv}$. Golden Torch was demonstrated by inoculation of detached leaves and inflorescences of that cultivar of heliconia. Susceptibility of ten heliconia cultivars to pestalotiopsis flower and leaf spot was evaluated on freshly cut inflorescences by inoculation of the fungus on previously injured areas of floral bracteas. The fungus had acervular conidiomata, epidermal to subepidermal, fusiform conidia, straight to slightly curved, measuring 21.0-26.5 x 6.5-8.5 $\mu \mathrm{m}$, four septates with the three median cells dark brown, three to five filiforme apical appendages, $8-15 \times 1.0 \mu \mathrm{m}$ and a basal pedicel, $5.0 \times 1.0 \mu \mathrm{m}$. The fungus was identified as Pestalotiopsis pauciseta. Inoculation of detached leaves and flowers by laying the culture disk of $P$. pauciseta over previously damaged tissues has demonstrated that the fungus is the etiological agent of this new heliconia disease. Evaluation of resistance to pestalotiopsis spot showed that $H$. rostrata and $H$. caribeae x $H$. bihai cv. Jacquinii were the most resistant among the tested cultivars. No lesions were produced on $H$. rostrata after inoculation. H. stricta cv. Las Cruzes was the most susceptible, followed by $H$. wagneriana. This is the first record of pestalotiopsis spot in heliconia and also the first report of heliconia resistance to this disease.
\end{abstract}

Additional keywords: ornamental plants, pathogenicity.

\section{INTRODUÇÃO}

As helicônias são plantas de origem neotropical, mais precisamente da região noroeste da América do Sul. Originalmente incluído na família Musaceae, o gênero Heliconia mais tarde passou a constituir a família monotípica Heliconiaceae (Castro, 1995). Existem aproximadamente 180 espécies descritas em Heliconia. Este é um dos gêneros mais importantes da floricultura tropical, destacando-se as espécies Heliconia psittacorum L.F., H. rostrata Ruiz \& Pav., H. bihai (L.) L., H. stricta Huber, H. wagneriana Petersen, $H$. angusta Vell., $H$. ortotricha L. Andersson $e H$. chartacea Lane ex Souza Barreiros. Cerca de 50 espécies são cultivadas comercialmente na região Nordeste do Brasil.

A floricultura comercial no Brasil se expandiu a partir da década de 70 , e desde esta época ocorreram mudanças bastante significativas no mercado nacional, com uma movimentação financeira em torno de US\$1,0 
bilhão e crescimento anual de 6,26\% (Sebrae, 2002). Em Pernambuco, como também em outros estados do Nordeste, as condições do clima permitem o cultivo de helicônias durante todo ano a um custo reduzido, tornando a região competitiva para esta cultura no mercado mundial. Os estados de Alagoas e Pernambuco começam a firmar posição como exportadores de flores tropicais de cortes, como as helicônias, notadamente dirigidas ao crescente mercado português (Coelho \& Warumby, 2002).

No Brasil, os estudos sobre problemas fitossanitários de plantas ornamentais têm sido objeto de diversos trabalhos (Pitta, 1995; Almeida et al., 1997), no entanto, os estudos sobre plantas ornamentais tropicais são ainda escassos. Assis et al. (2002) relacionaram 11 patógenos em helicônias, na maioria fungos agentes de manchas foliares e a bactéria Ralstonia solanacearum (Smith) Yabuuchi et al. Lins \& Coelho (2004), ao realizarem um levantamento de doenças nestas plantas em Pernambuco, assinalaram a presença da antracnose causada por Colletotrichum gloeosporioides (Penz.) Penz. \& Sacc., murcha de fusário causada por Fusarium oxysporum f. sp. cubense W.C. Snyder \& H.N. Hansen, diversas manchas foliares, causadas por espécies dos gêneros Bipolaris, Cercospora e Curvularia e fitonematoses que constituem sério problema no cultivo das helicônias.

Escalona et al. (1992) relataram na Venezuela uma nova doença em inflorescências de $H$. psittacorum x $H$. spathocircinata Aristeg. cv. Golden Torch, causada pelo fungo Myrothecium sp. Várias espécies fúngicas foram citadas por Madriz et al. (1991), na Venezuela, causando enfermidades em helicônia, tais como Phyllosticta musae F. Stevens \& E. Young, Glomerella cingulata (Stonman) Spauld. \& H. Schrenk, Alternaria alternata (Fr.) Keissl., Gloeosporium musarum Cooke \& Massee, Colletotrichum musae (Berk \& M.A. Curtis) Arx, Guignardia musae Racib., Curvularia sp., Fusarium oxysporum Schlecht., Mycosphaerella musicola R. Leach, Drechslera musae-sapientum (Hansf.) M.B. Ellis e Pestalotiopsis sp.

Medidas de controle citadas na literatura para doenças em plantas ornamentais tropicais, como manejo de adubação, sistema de plantio e irrigação (Coelho \& Warumby, 2002), muitas vezes não são efetivas. $\mathrm{O}$ controle químico tem sido usado de forma empírica, sem qualquer fundamentação em pesquisas científicas prévias ou consideração sobre a existência ou não de registro dos produtos utilizados. O uso de cultivares resistentes representaria uma alternativa de controle atraente para as principais doenças de flores tropicais.

A resistência genética e o controle biológico de doenças de plantas são métodos de controle que têm recebido especial atenção dos pesquisadores, pela vantagem de serem mais econômicos e evitarem a contaminação ambiental. A caracterização de fontes de resistência em germoplasma de plantas ornamentais tropicais pode revelar de imediato a existência de espécies/cultivares resistentes a serem utilizadas comercialmente em regiões ou condições favoráveis para o ataque de doenças, como a discutida neste trabalho, ou fornecer base genética para o melhoramento visando resistência.
Uma doença que afeta folhas e inflorescências de H.psittacorum x H. spathocircinata $\mathrm{cv}$. Golden Torch tem ocasionado perdas significativas na produção de flores tropicais no estado de Sergipe. Esta foi reconhecida como uma doença nova para ciência. O presente trabalho teve como objetivo descrever esta nova doença em helicônia, caracterizar morfologicamente o patógeno e avaliar a resistência em inflorescências de algumas espécies e cultivares ornamentais do gênero Heliconia.

\section{MATERIAL E MÉTODOS}

O isolado foi obtido em lesões de folhas de $H$. psittacorum $\mathrm{x}$ H. spathocircinata $\mathrm{cv}$. Golden Torch, proveniente da propriedade Flor da Terra em Umbaúba-SE em junho de 2004.

Após as etapas rotineiras de limpeza e desinfestação do material, fragmentos da região de transição, entre a lesão e os tecidos sadios (Menezes \& Assis, 2004) foram transferidos para placas de Petri contendo o meio de cultura batatadextrose-ágar (BDA) e, em seguida, incubados a $25 \pm 2{ }^{\circ} \mathrm{C}$, sob alternância luminosa fornecida por lâmpadas fluorescentes, (12h de claro/12h de escuro). Posteriormente, fragmentos do micélio foram removidos da colônia e transferidos para tubos de ensaio contendo BDA, sendo também preservados em água pelo método Castellani (Smith \& Onions, 1994). A cultura do fungo foi depositada na coleção da Micoteca do CEPEC-BA, sendo 72 o número do material depositado. Para identificação do gênero a que pertencia o fungo assim isolado utilizou-se a chave para coelomicetes de Sutton (1980) e o trabalho de Chen \& Wei (1993).

As características morfológicas do isolado do fungo foram avaliadas empregando-se a técnica de microcultura ou cultura em lâmina. A incubação foi feita em condições naturais de laboratório $\left(25^{\circ} \mathrm{C}\right.$, aproximadamente), durante 72 horas, sob condições de alternância luminosa ( $12 \mathrm{~h}$ de claro/ $12 \mathrm{~h}$ de escuro). Após este período, as lamínulas foram removidas, montadas em lâminas coradas com azul de Amann, e examinadas ao microscópio ótico para observação das estruturas formadas. Foi feita a medição do comprimento e largura de 100 conídios, estabelecendo-se uma média. Foram também observados os números de apêndices e a coloração das células.

Testes de patogenicidade foram realizados em folhas destacadas e inflorescências de $H$. psittacorum x $H$. spathocircinata cv. Golden Torch, em condições de laboratório a temperatura de $25{ }^{\circ} \mathrm{C}$, aproximadamente. As folhas foram acondicionadas em bandejas plásticas, revestidas com papel de filtro umedecido com água esterilizada, e envolvidas com saco plástico e as inflorescências mantidas em Erlenmeyers de $1000 \mathrm{ml}$, contendo $500 \mathrm{ml}$ de água destilada, também envolvidas em saco plástico. $\mathrm{O}$ inóculo foi depositado em porções de tecido intactas ou previamente feridas. Os ferimentos foram efetuados com auxílio de um estilete flambado. Depositou-se na superfície de folhas e brácteas intermediárias, discos de culturas formados em BDA. As inflorescências foram mantidas em câmara úmida durante 48 horas. As avaliações foram feitas 
sete dias após a inoculação, observando-se a reprodução dos sintomas.

Para caracterização da resistência foram avaliados os seguintes materiais de helicônia: H. bihai cv. Humilis, H. stricta cv. Las Cruzes, $H$. rostrata, $H$. wagneriana, $H$. psittacorum cv. Sassy e os híbridos H. caribeae Lamarck x $H$. bihai cv. Jacquinii, $H$. psittacorum x $H$. spathocircinata cv. Golden Torch, H. psittacorum x H. spathocircinata cv. Red Torch, $H$. psittacorum x H. spathocircinata cv. Golden Torch Adrian e $H$. psittacorum $\mathrm{x}$ H. spathocircinata $\mathrm{cv}$. Alan Carle.

Foram utilizadas inflorescências sadias, procedentes de Goiana-PE, desinfestadas com solução de hipoclorito de sódio a $2 \%$ por 2 min. $\mathrm{O}$ experimento foi conduzido em condição de laboratório com temperatura de $25 \pm 2{ }^{\circ} \mathrm{C}$ e $90 \%$ de U.R. As inflorescências foram colocadas em Erlenmeyers com capacidade de $1000 \mathrm{ml}$, contendo água destilada esterilizada até metade do recipiente, mantendo-se três hastes/Erlenmeyer.

O patógeno foi cultivado em placas de Petri contendo meio de batata-dextrose-agar (BDA) e incubado durante sete dias em temperatura aproximada de $25{ }^{\circ} \mathrm{C}$. A inoculação foi realizada com a produção prévia de ferimentos produzidos com estilete flambado no meio da superfície externa das primeiras brácteas abertas, e depositando-se na superfície do tecido ferido, discos de $5 \mathrm{~mm}$ de diâmetro de cultura do fungo produzida em BDA. As inflorescências foram mantidas em câmara úmida durante 48 horas para favorecer a colonização do patógeno. Para as testemunhas repetiram-se os mesmos procedimentos, porém sendo depositados somente discos de BDA. A avaliação foi realizada aos sete dias após a inoculação, através da medida do comprimento e largura das lesões e observação das características das lesões.

O delineamento experimental utilizado foi inteiramente casualizado com quatro repetições, sendo cada repetição constituída por um Erlenmeyer com três hastes, cada haste com dois pontos de inoculação, nas brácteas intermediarias. Cada repetição possuía um total de seis pontos de inoculação, onde se obtinha um valor médio desses seis tamanhos de lesões/repetição. Os dados foram submetidos à análise de variância e as médias comparadas pelo teste de Duncan ao nível de 5\% de probabilidade. Os dados obtidos foram transformados em $\sqrt{ } \mathrm{x}+0,5$. A avaliação foi realizada aos sete dias após a inoculação, através da medida do comprimento e largura das lesões e observação das características das lesões.

\section{RESULTADOS E DISCUSSÃO}

Nos isolamentos realizados a partir dos fragmentos de tecido infectado, culturas de uma única espécie fúngica foram obtidas. As colônias caracterizaram-se por apresentar coloração branca, micélio vigoroso, algodonoso e esporulação abundante, em massas negras de conídios.

As lesões nas brácteas caracterizaram-se por manchas deprimidas, ovaladas a elípticas, com centro branco acinzentado e bordos de coloração marrom avermelhado, medindo 0,7 - 2,5 x 0,5 a $1,0 \mathrm{~cm}$. Pontuações escuras, correspondentes aos acérvulos do fungo, foram observadas no centro das lesões (Figura 1A). Nas folhas as manchas eram ovaladas, de coloração marrompalha, bordos regulares, envolvidas por halo amarelado. No
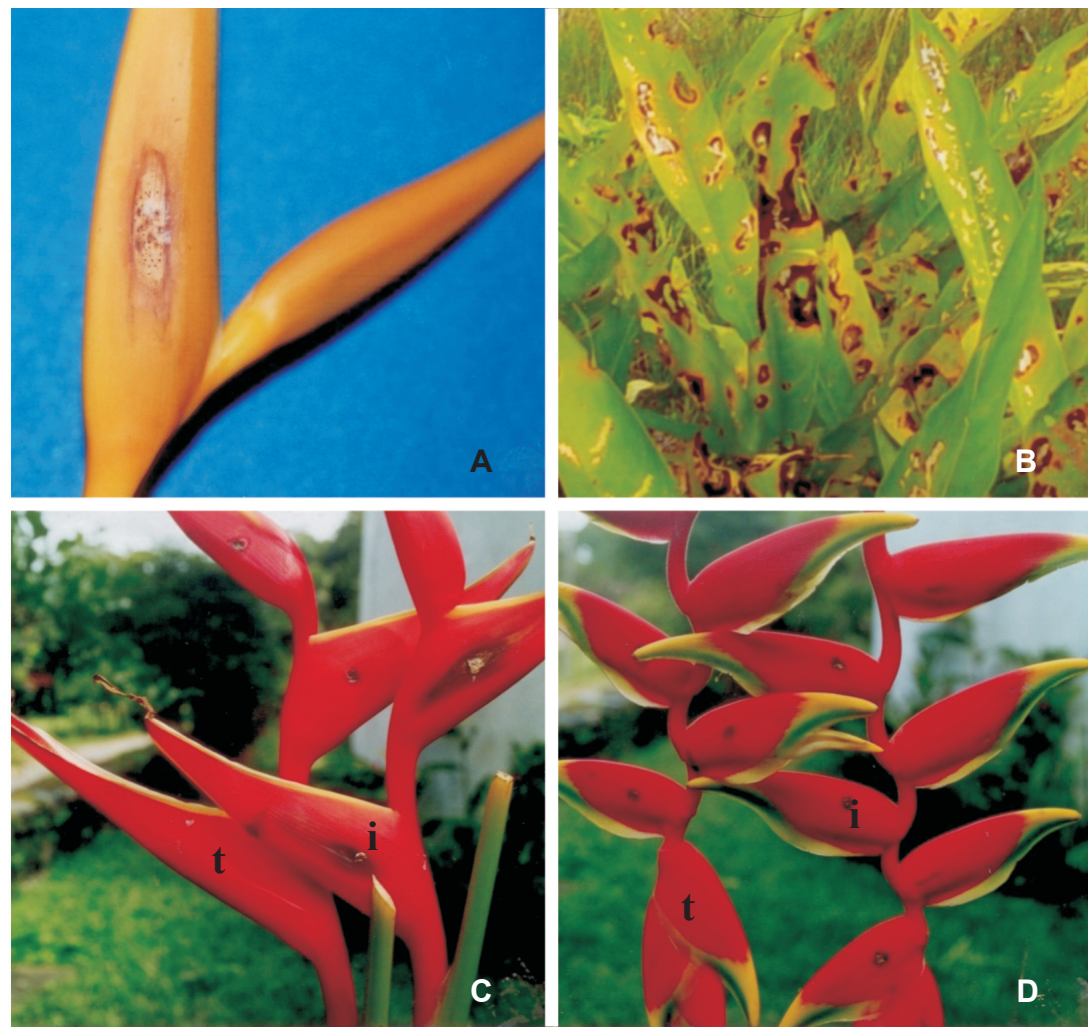

FIG. 1 - Pestalotiopsis pauciseta. A. Lesão em bráctea de $H$. psittacorum $\mathrm{x} H$. spathocircinata cv. Golden Torch; B. Sintomas da mancha foliar de pestalotiopsis em plantas de $H$. spathocircinata cv. Golden Torch no campo; C. Reação de suscetibilidade à mancha de pestalotiopsis em $H$. stricta cv. Las Cruzes; D. Reação de resistência à mancha de pestalotiopsis em $H$. rostrata (t-testemunha; i-inoculada). 
centro das lesões formaram-se muitos acérvulos do fungo, nas faces superior e inferior da folhas, caracterizados como pontuações escuras. As manchas freqüentemente coalesciam formando extensas áreas necrosadas, com rasgamento do tecido (Figura 1B).

Considerando a morfologia exibida no cultivo, o referido fungo pertence à espécie Pestalotiopsis pauciseta (Sacc.) Y.X Chen, segundo Chen \& Wei (1993). O fungo apresentava micélio imerso, septado, ramificado, hialino tornando-se castanho claro; acérvulo anfígeno, epidérmico a subepidérmico, punctiforme, tornando-se erumpente, $200-250 \mu \mathrm{m}$ de diâmetro, parede fina composta de textura angulares; conidióforos hialinos, conídios fusiformes, retos a levemente curvados, medindo 21,0-26,5 x 6,5$8,5 \mu \mathrm{m}$, com cinco células, sendo as três medianas marrons e as apicais hialinas sem constrição nos septos; célula apical com três a cinco apêndices filiformes, $8-15 \times 1,0 \mu \mathrm{m}$; pedicelo basal curto, medindo 5,0 x 1,0 $\mu \mathrm{m}$.

Pestalotiopsis pauciseta ainda não havia sido relatado no Brasil causando doença em espécies de helicônia. Outros relatos de Pestalotiopsis sp., associado a helicônia na Venezuela e Havaí, já haviam sido publicados (Madriz et al, 1989; Sewake \& Uchida, 1995).

Este fungo tem sido pouco mencionado como patógeno de importância em flores tropicais, embora citado como agente de lesões foliares em helicônias (Madriz et al., 1989; Sewake \& Uchida, 1995). Pestalotiopsis é um gênero complexo e a classificação á nível especifico é bastante dificultada, pela enorme variação da morfologia aceita para as diferentes espécies do gênero (Jeewon et al., 2003) Tradicionalmente a caracterização taxonômica desse fungo tem sido baseada na morfologia de conídios (Nag Rag, 1993), conidiogênese (Sutton, 1980) e associação com o teleomorfo, descrito somente para algumas espécies (Metz et al., 2000). Desde o estabelecimento do gênero (Steyaert, 1949), diversos estudos taxonômicos têm sido conduzido na tentativa de sugerir uma classificação mais adequada, na combinação das diferentes espécies de Pestalotiopsis (Chen \& Wei, 1993; Nag Rag, 1993).

As inflorescências e folhas de Golden Torch inoculadas exibiram lesões somente quando inoculadas com ferimento. $\mathrm{O}$ patógeno foi reisolado das lesões e identificado como o mesmo fungo inoculado. Conforme Menezes (2005) e Furtado (2005), as espécies do gênero Pestalotiopsis penetram nos tecidos do hospedeiro através de aberturas naturais, ferimentos e lesões provocadas por outros patógenos. Assim como observado neste trabalho, testes de patogenicidade realizados com Pestalotiopsis psidii (Pat.) Mordue em caule de goiabeira (Psidium guajava L.) e Pestalotiopsis sp. em folhas de coqueiro (Cocus nucifera L.), resultaram na formação de lesões apenas com a inoculação por ferimento (Cardoso et al., 2002, 2003). Os resultados do teste de patogenicidade demonstram que Pestalotiopsis pauciseta é o agente etiológico de uma nova doença em helicônia no Brasil.

No teste de patogenicidade em folhas, as lesões tinham as mesmas características daquelas observadas no campo, embora sem apresentar a queda do tecido necrosado, provavelmente pelo tempo de avaliação em folhas destacadas não ter sido suficiente para expressão deste sintoma. É possível, também, que a mancha perfurada ocorra devido a associação com outros fitopatógenos ou saprófitas, embora nos isolamentos dos tecidos infectados somente tenham surgido colônias de Pestalotiopsis pauciseta. Conforme Araújo et al. (1991), as espécies de Pestalotiopsis que afetam plantas da família Arecaceae são consideradas patógenos fracos (infectam áreas previamente feridas) e ocorrem associados a outros fitopatógenos. Em relação a este aspecto, Cardoso et al. (2002) verificaram que $P$. psidii e Lasiodiplodia theobromae (Pat.) Griff. \& Maubl. causavam, independentemente, podridão em caule de goiabeira. No entanto, a inoculação simultânea deste fitopatógenos promovia a formação de lesões que ultrapassavam o dobro do tamanho das lesões de cada fungo. Algumas espécies do gênero Pestalotiopsis são reconhecidas como fitopatógenos primários por alguns autores (Keith et al., 2006; Vitale \& Polizzi, 2005; Camili et al., 2002). Foram observadas diferenças estatísticas significativas entre as espécies e cultivares de helicônia quanto a resistência à mancha de pestalotiopsis (Tabela 1).

TABELA 1 - Médias de comprimento e largura das lesões formadas em brácteas de diferentes espécies e cultivares de helicônia, causadas por Pestalotiopsis pauciseta sete dias após a inoculação

\begin{tabular}{|c|c|c|}
\hline Espécies/Cultivares & Comprimento (cm) & Largura $(\mathrm{cm})$ \\
\hline H. stricta $\mathrm{cv}$. Las Cruzes & $4.50 \mathrm{a}$ & $1,30 \mathrm{a}$ \\
\hline H. wagneriana & $1.87 \mathrm{~b}$ & $0,70 \mathrm{~b}$ \\
\hline H. psittacorum x H. spathocircinata cv. Red Torch & $1.62 \mathrm{bc}$ & $0,47 \mathrm{~b}$ \\
\hline H. psittacorum x H. spathocircinata cv. Golden Torch Adrian & $1.47 \mathrm{bc}$ & $0,62 \mathrm{~b}$ \\
\hline H. psittacorum $\mathrm{x}$ H. spathocircinata cv. Alan Carle & $1.10 \mathrm{c}$ & $0,52 \mathrm{~b}$ \\
\hline H. psittacorum cv. Sassy & $1.07 \mathrm{c}$ & $0,50 \mathrm{~b}$ \\
\hline H. bihai $\mathrm{cv}$. Humilis & $1.02 \mathrm{c}$ & $0,62 \mathrm{~b}$ \\
\hline H. psittacorum x H. spathocircinata cv. Golden Torch & $0.95 \mathrm{c}$ & $0,57 \mathrm{~b}$ \\
\hline H. caribeae $\mathrm{x} H$. bihai $\mathrm{cv}$. Jacquinii & $0.25 \mathrm{~d}$ & $0,25 \mathrm{c}$ \\
\hline H. rostrata & $0,00 \mathrm{~d}$ & $0,00 \mathrm{~d}$ \\
\hline C.V & 12,41 & 6.82 \\
\hline
\end{tabular}

*Média de quatro repetições. Letras minúsculas no sentido vertical não diferem ao nível de $5 \%$ de probabilidade pelo teste de Duncan. Os dados foram transformados em $\sqrt{ } \mathrm{x} .+0,5$. 
Em relação ao tamanho das lesões, o material mais suscetível foi $H$. stricta cv. Las Cruzes, apresentando as maiores médias, diferindo estatisticamente das demais ao nível de 5\% de probabilidade (Figura 1C). A espécie $H$. rostrata foi o material mais resistente $(\mathrm{P} \leq 0,05)$ não sendo formadas quaisquer lesões após a inoculação (Figura 1D). $\mathrm{O}$ segundo material mais resistente foi H.caribeae x $H$. bihai cv. Jacquinii que apresentou lesões de menores dimensões, quando comparados aos demais materiais. Madriz et al. (1991) estudaram a ocorrência de fungos fitopatogênicos presentes em folhas de algumas espécies de Heliconia, na Venezuela, e observaram para Pestalotiopsis sp. uma incidência de $62 \% \mathrm{em} H$. psittacorum, $35,3 \% \mathrm{em} H$. latisphata Benth., 6,5 em $H$. caribeae e $0 \%$ em $H$. rostrata. Com exceção de $H$. rostrata, H.caribeae x $H$. bihai cv. Jacquinii e $H$. bihai cv. Humilis observou-se uma abundante esporulação do fungo na superfície das brácteas inoculadas, mesmo quando as lesões eram pequenas.

De acordo com os resultados, pode se observar que o híbrido H. psittacorum $\mathrm{x}$ H. spathocircinata cv. Golden Torch mostrou-se moderadamente resistente, apresentando apenas lesões pequenas nos pontos inoculados. Considerando-se que o isolado havia sido obtido de lesões de folha desse híbrido de helicônia, esperava-se que o mesmo apresentasse suscetibilidade elevada ao fungo, possivelmente isso não ocorreu devido à diferença que pode existir entre a resistência do tecido das folhas e das brácteas. Resultados semelhantes foram observados por Coelho \& Warumby (2004) que concluíram que somente folhas de $H$. psittacorum x $H$. spathocircinata $\mathrm{cv}$. Golden Torch são suscetíveis a $C$. gloeosporioides, enquanto que as inflorescências mostraramse resistentes.

Dentre os materiais avaliados no experimento, $H$. rostrata, H.caribeae x $H$. bihai cv. Jacquinii se destacaram por apresentarem níveis satisfatórios de resistência a mancha de pestalotiopsis nas brácteas florais. Este é o primeiro relato da ocorrência de materiais de helicônia resistentes a mancha de pestalotiopsis.

\section{AGRADECIMENTO}

Os autores agradecem a Dra. Maria Menezes (Universidade Federal Rural de Pernambuco) pela valiosa contribuição ao trabalho, e ao Dr. José Luiz Bezerra (CEPEC) pela identificação da espécie fúngica.

\section{REFERÊNCIAS BIBLIOGRÁFICAS}

ALMEIDA, I.M.G., MALAVOLTA JUNIOR, V.A \& IMEMES, S.L. (Eds.) Problemas Fitossanitários em Plantas Ornamentais. Instituto Biológico de Campinas, Campinas, 1997.

ARAÚJO, J.C.A., GASPAROTTO, L. \& GARCIA, M.V.B. Epidemiologia de Pestalotiopsis guepinii em coqueiro no Distrito
Federal. Fitopatologia Brasileira 16:33. 1991. (Resumo)

ASSIS, S.M.P., MARIANO, R.R.L, GONDIM JUNIOR, M.G.C., MENEZES, M. \& ROSA, R.C.T. Doenças e pragas das helicônias. Diseases and pests of heliconias. Recife PE. Universidade Federal Rural de Pernambuco. 2002

CAMILI, E.C., CARBONARI, M. \& SOUZA, N.L. Caracterização de Pestalotiopsis longisetula e sua patogenicidade em morango. Summa Phytopathologica 28:213-214. 2002.

CARDOSO, J.E., MAIA, C.B. \& PESSOA, M.N.G. Ocorrência de Pestalotiopsis psidii e Lasiodiplodia theobromae causando podridão no caule de goiabeira no Ceará. Fitopatologia Brasileira 27:320. 2002. (Resumo)

CARDOSO, G.D., BARRETO, A.F., ARAÚJO, E., ALMEIDA, F.A. \& CARVALHO, R.A.G. Etiologia e progresso da mancha de Pestalotia do coqueiro (Cocos nucifera L.), em São Gonçalo, Paraíba. Revista Brasileira de Fruticultura 25:335-336. 2003.

CASTRO, C.E.F. Helicônia para exportação: aspectos técnicos da produção. Brasília DF. EMBRAPA. 1995. (Série Publicações Técnicas FRUPEX, 16).

CHEN, Y.X. \& WEI, Q. Ten new combinations of the genus Pestalotiopsis from China. Journal of Guangxi Agricultural University 24:141-150. 1993.

COELHO, R.S.B. \& WARUMBY, J.F. Doenças de plantas ornamentais tropicais detectadas na Zona da Mata de Pernambuco. Floricultura em Pernambuco (Recife) 1:67-69. 2002.

COELHO, R.S.B. \& WARUMBY, J.F. Curso de Doenças e Pragas de Plantas Ornamentais Tropicais. EMDAGRO/SAGRI/SE, Aracaju (Mimeografado). 2004

ESCALONA, F., MACIEL, N. \& RENAUD, J. Un manchado de las inflorescencias de heliconias. Fitopatologia Venezuelana 5:3032. 1992.

FURTADO, E.L. Doenças do chá-preto. In: Kimati, H., Amorim, L., Rezende, J.A.M., Bergamin Filho, A. \& Camargo, L.E.A. (Eds.) Manual de Fitopatologia. Doenças de plantas cultivadas, $4^{\mathrm{a}}$ ed. São Paulo SP. Editora Ceres. 2005. pp. 235-238.

KEITH, L.M., VELASQUEZ, M.E. \& ZEE, F.T. Identification and characterization of Pestalotiopsis spp. causing scab disease of guava, Psidium guajava, in Hawaii. Plant Disease 90:16-23. 2006.

JEEWON, R., LIEW, E.C.Y., SIMPSON, J.A., HODGKISS, I.J. \& HYDE, K.D. Phylogenetic significance of morphological characters in the taxonomy of Pestalotiopsis species. Molecular Phylogenetics and Evolution 27:372-383. 2003.

LINS, S.R.O. \& COELHO, R.S.B. Ocorrência de doenças em plantas ornamentais tropicais no Estado de Pernambuco. Fitopatologia Brasileira 29:332-335. 2004.

MADRIZ, R., NOGUERA, R. \& SMITS, G.B. Patogenos foliares en Heliconia psittacorum L. Fitopatologia Venezuelana 2:61. 1989. (Resumen)

MADRIZ, R., SMITS, G.B. \& NOGUERA, R. Principales hongos patogenos que afectan algunas especies ornamentales del genero Heliconia. Agronomía Tropicale, Venezuela, Maracay 41:265-274. 1991.

MENEZES, M. Doenças do cajueiro. In: Kimati, H., Amorim, L., Rezende, J.A.M., Bergamin Filho, A. \& Camargo, L.E.A. (Eds.) Manual de Fitopatologia. Doenças de plantas cultivadas, $4^{\mathrm{a}}$ ed. São Paulo SP. Editora Ceres. 2005. pp. 181-184. 
MENEZES, M. \& ASSIS, S.M.P. Guia prático para fungos fitopatogênicos. Recife PE. Imprensa Universitária da UFRPE. 2004.

METZ, A.M., HADDAD, A., WORAPONG, J., LONG, D.M., FORD, E.J., HESS, W.M. \& STROBEL, G.A. Induction of the sexual stage of Pestalotiopsis microspora, a taxol-production fungus. Microbiology 146:2079-2089. 2000.

NAG RAG, T.R. Coelomycetous anamorphs with appendage bearing conidia. Ontario. Mycologue Publications. 1993.

PITTA, G.P.B. Flores e plantas ornamentais para exportação: aspectos fitossanitários. Brasília DF. EMBRAPA SP. 1995. (Publicações Técnicas FRUPEX, 17).

SEBRAE. Floricultura em Pernambuco. Recife PE. SEBRAE/PE,
2002. (Série Agronegócio, 01).

SEWAKE, K.T. \& UCHIDA, J.Y. Diseases of Heliconia in Hawaii. Research extension series/ Hawaii Intitute of Tropical Agriculture and Human Resources 001. 1995.

SMITH, D. \& ONIONS, A.H.S. The preservation and maintenance of living fungi. Egham: International Mycological Institute. 1994.

SUTTON, B.C. The Coelomycetes: Fungi Imperfecti with Pycnidia, Acervuli and Stromata. Kew. Commonwealth Mycological Institute. 1980

VITALE, A. \& POLIZZI, G. Occurrence of Pestalotiopsis uvicola causing leaf spots and stem blight on bay laurel (Laurus nobilis) in Sicily. Plant Disease 89:1362. 2005.

Recebido 14 Fevereiro 2005 - Aceito 09 Fevereiro 2007 - FB 5008 